\section{TGN1412: scrutinizing preclinical trials of antibody-based medicines}

SIR - Your News story about the recent clinical-trial disaster, "Can super-antibody drugs be tamed?" (Nature 440, 855-856; 2006), reports TeGenero founder Thomas Hünig as saying that the monkey CD28 receptor - the target of the TGN1412 antibody - is identical to the human one. TeGenero's 'investigator's brochure' (available via www.mhra.gov.uk) confirms that toxicity testing of TGN1412 was done in rhesus and cynomolgus monkeys.

Although TeGenero says that the aminoacid sequence of the critical portion of monkey CD28 (the C"D loop) is identical to that of human CD28, published amino-acid and DNA sequence data on rhesus CD28 indicate substantial genetic diversity within the species. Differences of up to $4 \%$ (9 of 220 amino acids) between rhesus and human proteins have been found (F. Villinger et al. Immunogenetics 53, 315-328; 2001).

No data are available for CD28 in cynomolgus monkeys, but as they are closely related to rhesus monkeys, a similar degree of variation can be expected.

Two variable positions in the rhesus CD28 sequence - amino acid 65 (glutamic acid or glycine) and 104 (asparagine or tyrosine) - are located on the edge of the contact region between human CD28 and TGN1412. Although they may be tolerated, they are likely to substantially affect the strength of antibody-antigen interaction.

Identity of sequence in the $\mathrm{C}^{\prime \prime} \mathrm{D}$ loop is also insufficient as a criterion for compatibility, as this segment contains only 6 of the 12 amino acids of CD28 that make contact with TGN1412. Substitutions at any position in this area might be expected to affect the shape of the antigenic site. Binding of the antibody to rhesus CD28 could therefore potentially be much weaker than its binding to human CD28. And differences in the binding affinities could alter the balance between activation of regulatory $\mathrm{T}$ cells (bearing relatively high levels of CD28), on the one hand, and T-helper cells and eosinophilic granulocytes (with lower CD28 expression), on the other (G. Woerly et al. J. Exp. Med. 190, 487-495; 1999).

We propose that future preclinical studies of antibody-based drugs should be performed using a primate species in which the antigenic site matches that in humans completely, and that the individual primates used should be genotyped to exclude polymorphisms.

Furthermore, preclinical studies should also include comparative measurements of the binding affinities for both human antigen and primate antigen, to control for unforeseen variations in protein structure. Søren Hansen, R. Graham Q. Leslie Medical Biotechnology Center and Institute of Medical Biology, University of Southern Denmark, Winslowparken 25, DK-5000, Denmark

\section{Drug giants hamstrung by timid middle management}

SIR - Your Business story "Too little, too late" (Nature 440, 603; 2006) discusses a merger between Bayer and Schering, implying that the move is needed to make them large enough to succeed. My experience, during 50 years' research in big pharma, is the opposite. Large companies are always inefficient because their command structure makes them so. Any organization with many layers, where power flows from the top down, works against innovation look at the widely reported depletion of bigbudget companies' pipelines (see Nature 439, 886-887; 2006).

The reason is that people in the middle layers, who neither control events nor engage in discovery, are too afraid to respond favourably to genuinely new ideas. If they encourage one and then it flops, as most innovations do, they are marked for demotion or dismissal. But if they kill novel programmes, nobody will ever know that a great thing died before it was born, and they are safe. The top layers cannot evaluate research themselves, because so much information is generated at the bench that they are forced to delegate most up-or-down decisions to middle management. Nowadays most of the innovation takes place in small outfits, because it is not crushed there.

Raymond A. Firestone

59 Barnes Road, Stamford,

Connecticut 06902, USA

\section{ID paper wasn't impartial enough for committee}

SIR - As a former member of the Board of the Social Sciences and Humanities Research Council of Canada (SSHRC), I read with some irritation your News story "Doubts over evolution block funding by Canadian agency" (Nature 440, 720-721; 2006).

The proposed study of the effects of popularization of intelligent design was, in fact, simply rejected and thus could not be "blocked" by the council. Given that the average success rate is less than $40 \%$, the majority of applicants are bound to fail.

In this case, an excerpt from the rejection letter, lifted from its context, has been used to suggest that the committee felt there was inadequate "justification for the assumption in the proposal that the theory of evolution, and not intelligent-design theory, was correct". But this excerpt can be interpreted in a less dramatic manner: the committee simply thought the study was not impartial enough in its approach. After all, social-science research should study phenomena and not promote a particular view; many scholars legitimately demand a symmetric approach.

One can, of course, disagree with such comments, and many researchers do when they do not get their funding. But the author in this case is misguided in his view that the rejection "illustrates how the misunderstanding of evolution and intelligent design can go to all levels of Canadian society".

The SSHRC does not interfere with peerreview committees. Instead of pointing his finger at the SSHRC, the researcher should complain about his peers who were not convinced by his proposal or, better still, he should learn from their comments. Yves Gingras

Département d'histoire, Centre interuniversitaire de recherche sur la science et la technologie, Université du Québec à Montréal, case postale 8888 , succursale Centre-ville, Montréal, Québec H3C 3P8, Canada

\section{Supporting the use of artemisinin in combination}

SIR - Your News story "Malaria breakthrough raises spectre of drug resistance" (Nature 440, 852-853; 2006) raises concerns about a new source of artemisinin for treating malaria. The Institute for OneWorld Health (IOWH) strongly supports the World Health Organization guideline that uncomplicated falciparum malaria be treated with artemisinin combination therapies, and not by artemisinin alone as a monotherapy.

We are leading the product development effort for the Artemisinin Project in the developing world and will sell microbially derived artemisinin only for the manufacture of combination antimalarial therapies, except for treatments of severe malaria with parenteral formulations of artemisinin derivatives.

By leveraging the promise of synthetic biology, the IOWH and its partners hope to dramatically reduce the cost of antimalarials for the people who most need them.

Victoria G. Hale

Institute for OneWorld Health, 50 California Street, San Francisco, California 94111, USA

Contributions to Correspondence may be submitted to corres@nature.com.They should be no longer than $\mathbf{5 0 0}$ words, and ideally shorter. They should be signed by no more than three authors; preferably by one. Published contributions are edited. 